\title{
A Review of Issues Related to Copper Etchant.
}

\author{
S. A. Patil ${ }^{1}$, R.P Yadav ${ }^{2}$ \\ Mechanical Engineering/ SSJCET College, India
}

\begin{abstract}
Copper etching is considerably important process in electronics industry, particularly in the fabrication of printed circuit board. Various etchants can be used for this purpose, but nowadays cupric chloride is more accepted etchant, because of its high etch rate and easy regeneration properties. In the present study, copper etching process with cupric chloride etchant was investigated. In the etching of copper, the most important etching parameter is etch rate, therefore the investigation was based on the various effects on etch rate. The influence of etchant concentration, additives and etching temperature were examined. It is also important to regeneration/recycle of waste etchant from environmental point of view. Thus, various cupric chloride etchant regeneration processes were investigated.
\end{abstract}

Keywords: - Copper etchants, Cupric Chloride, Ferric Chloride, Alkaline Etchants, and Regeneration of waste etchant.

\section{INTRODUCTION}

Etching is one of the important non-traditional machining processes to produce geometrically complex machine parts from thin and flat sheets. This process is widely used in electronics, aerospace and precision engineering industries. Etching is the main machining step in chemical and photochemical machining processes .

Etching is known as photochemical machining, wet etching, photo etching, photochemical milling etc. First application was carried out to produce jewelries from copper in the Ancient Egypt in B.C. 2500. The important development was established by aerospace/aircraft manufacturers around 1950's and electronics industry pushed its limits for major application such as printed circuit board manufacturing and other electronic components.

The application of etching has widely been used in the manufacturing of thin, flat and complex metal parts (i.e. lead frames, color TV masks, sensors, heat plates, printed circuit boards) in electronics, precision engineering and decorative industries in the past thirty years. Its economical advantages has been established over rival processes like wire electro-discharge machining, laser beam machining and stamping. PCM has also been used in the production of micro components for the micro technology recently.

Copper etching is the main process in the printed circuit board (PCB) manufacturing for electronics application. Historically, the first etchant in PCB fabrication was ferric chloride $\left(\mathrm{FeCl}_{3}\right)$ and it is still used as an etchant for small scale production lines. However, last two decades, new etchants have been introduced for copper etching. One of them was cupric chloride $\left(\mathrm{CuCl}_{2}\right)$. Nowadays, it has been major etchant in copper etching industry.

In this study, copper etching with $\mathrm{CuCl} 2$ was investigated. The effects of etchant concentration, additives and etching temperature on etch rate of copper were examined. It is also important that the regeneration/recycle etchant should be available because of environmental restrictions. The regeneration processes for waste $\mathrm{CuCl} 2$ have been determined.

\section{ETCHANTS IN COPPER ETCHING}

The ideal etchant for copper should have some properties such as high etch rate, minimum undercut, high dissolved copper capacity, easy control, economic regeneration of waste etchant and copper recovery [58]. Basically, there have been widely accepted three etchants for copper etching. These were $\mathrm{CuCl}_{2}, \mathrm{FeCl}_{3}$ and alkaline etchants. There are other etchants can be mentioned, but their use have been very limited or unused due to their environmental hazardous properties.

$\mathrm{CuCl}_{2}$ is a suitable etchant in etching "print and etch" type PCB at a larger scale. These PCBs are single sided board and requires economical etchant. $\mathrm{CuCl}_{2}$ provides high etch rate when compared with $\mathrm{FeCl}_{3}$ and produces low undercut. The copper dissolve capacity of $\mathrm{CuCl}_{2}$ is three times higher than $\mathrm{FeCl}_{3}$. The full regeneration advantage of $\mathrm{CuCl}_{2}$ makes it attractive etchant to etching industry. It is also used as an etchant for copper alloys such as brass, bronze, beryllium copper, etc. Alkaline etchants are only used for copper. These 
etchants are provided by supplier and the supplier takes waste etchant back for regeneration/recovery of etchant and copper. Alkaline etchants are expensive, therefore they are used for bulk production processes. Table 1 presents some characteristics of $\mathrm{CuCl}_{2}, \mathrm{FeCl}_{3}$ and alkaline etchants.

Table 1. Some etchants characteristics in PCB fabrication

\begin{tabular}{|l|l|l|l|l|}
\hline Etchant & Corrosiveness & $\begin{array}{l}\text { Neutralization and } \\
\text { Disposal problems }\end{array}$ & Toxicity & $\begin{array}{l}\text { Operational } \\
\text { Cost* }\end{array}$ \\
\hline $\begin{array}{l}\text { Cupric } \\
\text { Chloride }\end{array}$ & High & Low & Medium & Low \\
\hline $\begin{array}{l}\text { Ferric } \\
\text { Chloride }\end{array}$ & High & Medium & Low & Medium \\
\hline $\begin{array}{l}\text { Alkaline } \\
\text { Etchants }\end{array}$ & High & Medium & Medium & High \\
\hline
\end{tabular}

(*) Include disposal cost.

\section{COPPER ETCHING}

$\mathrm{CuCl}_{2}$ is a rather messy, yellow-brown, hygroscopic solid, usually sold as the green crystalline dihydrate salt, $\mathrm{CuCl}_{2} \cdot 2 \mathrm{H}_{2} \mathrm{O}$. It is commonly used acidic and comprises the copper salt, water and hydrochloric acid ( $\left.\mathrm{HCl}\right)$.

The etching of copper with $\mathrm{CuCl}_{2}$ can be expressed by the following chemical equation;

$$
\mathrm{CuCl}_{2}+\mathrm{Cu} \rightarrow 2 \mathrm{CuCl}
$$

The copper surface gets attacked by $\mathrm{CuCl}_{2}$ while cuprous chloride $\left(\mathrm{CuCl}_{2}\right)$ is formed. One copper atom with one cupric ion produces two cuprous ions. Copper etching with $\mathrm{CuCl} 2$ solution is controlled strongly during the etching process.

The molarity of cupric chloride etchant solution is important characteristic. It is represented by Baumé and 32-33 ${ }^{\circ}$ Bé (2.33-2.5 Mol) gives high and stable etch rate for copper etching. Lower of this degree gives low etch rate with poor line resolution and higher Bé degrees produces slow etch rate with a smooth line resolution.

The etching temperature considerably affects etching process. Using higher etching temperature increases the etch rate for copper etching with cupric chloride. It is obtained low etch rate by using low etching temperature. However, the temperature of etching is maintained around $50^{\circ} \mathrm{C}$. This is due to etching machine, because etchant affects metallic parts of machine at higher temperatures. The etch rate of copper at $32{ }^{\circ}$ Bé $(2.33 \mathrm{Mol})$ and $50^{\circ} \mathrm{C}\left( \pm 2^{\circ} \mathrm{C}\right)$ etching temperature is around $10 \mu \mathrm{m} / \mathrm{min}$

Basically, when $\mathrm{CuCl}_{2}$ solution is prepared, small amount $\mathrm{HCl}$ is added to solution. The effect of $\mathrm{HCl}$ addition to $\mathrm{CuCl} 2$ maintains high etch rate that is shown in Table 2. It is also known that the copper dissolve capacity increases by additional $\mathrm{HCl}$.

Table 2. $\mathrm{HCl}$ addition effect on the etch rate

\begin{tabular}{|l|l|l|l|}
\hline $\mathbf{C u C l} 2$ & $\begin{array}{l}\text { Etching } \\
\text { Temperature }\left({ }^{\circ} \mathbf{C}\right)\end{array}$ & HCl Addition & Etch Rate (mm/min) \\
\hline $33^{\circ}$ Bé $(2.5 \mathrm{Mol})$ & 49 & $1 \mathrm{~N}(1 \mathrm{Mol})$ & 25 \\
\hline $33^{\circ}$ Bé $(2.5 \mathrm{Mol})$ & 49 & $2 \mathrm{~N}(2 \mathrm{Mol})$ & 31 \\
\hline $33^{\circ}$ Bé $(2.5 \mathrm{Mol})$ & 49 & $3 \mathrm{~N}(3 \mathrm{Mol})$ & 38 \\
\hline
\end{tabular}

(The calculation of Baumé is done as follows: Bé=145 [(sg-1)/sg] where sg: specific gravity)

The additions of various chemical additives to $\mathrm{CuCl}_{2}$ produces better etching properties. The addition of ammonium chloride $(\mathrm{NH} 4 \mathrm{Cl})$ to $\mathrm{CuCl} 2$ provides high etch rate and increases copper dissolved as the same level of $\mathrm{HCl}$ addition. $\mathrm{CuCl} 2$ with $15 \%$ ammonium chloride could gives four times higher etch rate than $\mathrm{CuCl} 2$ [5]. Some chemical additives such as monomethanol amine, ethanol, acetonitrile, acetone, dimethyl formamide to $\mathrm{CuCl}_{2}$ also increase the etch rate of copper. 
This positive effect causes some difficulties on the regeneration of waste etchant. Therefore, it is general approach to keep etchant as simple as possible.

\section{REGENERATION OF WASTE ETCHANT}

The regeneration/recycle is the most important advantage of $\mathrm{CuCl}_{2}$. It is noticed that waste $\mathrm{CuCl}_{2}$ can completely be regenerated. There are various regeneration processes available for $\mathrm{CuCl}_{2}$. $\mathrm{Chemical}$ regeneration basically is being used by etching companies, due to of pure $\mathrm{CuCl}_{2}$ price. After regeneration, surplus $\mathrm{CuCl}_{2}$ can sell to chemical companies for further utilizing. A recovery copper from spent solution by electrolytic method can be more available for companies. This would cause no disposal problem and to sell obtained pure copper from

Solution.

The chemical regeneration of waste $\mathrm{CuCl}_{2}$ is completed by adding one of the following chemicals to spent solution:

\section{Chlorine Gas}

$2 \mathrm{CuCl}+\mathrm{Cl}_{2} \stackrel{\mathrm{HCl}}{\rightarrow} \quad \mathbf{2 ~ C u C l}_{2}$

\section{Hydrogen Peroxide and Hydrochloric Acid}

$2 \mathrm{CuCl}+\mathrm{H}_{2} \mathrm{O}_{2}+\mathrm{HCl} \rightarrow 2 \mathrm{CuCl}_{2}+2 \mathrm{H}_{2} \mathrm{O}$

\section{Sodium Chlorate and Hydrochloric Acid}

$$
2 \mathrm{CuCl}+1 / 3 \mathrm{NaClO}_{3}+2 \mathrm{HCl} \rightarrow 2 \mathrm{CuCl}_{2}+1 / 3 \mathrm{NaCl}+\mathrm{H}_{2} \mathrm{O}
$$

\section{- ADVANTAGES:}

1. It can be produce geometrically complex machine parts from thin and flat sheets.

2. Copper etching process completed at the highest etching temperature.

3 . Etching parameters would produce stable etch rate and low undercut in copper etching.

4. It has a stable etch quality rate under uniform process conditions.

5. Regeneration of waste $\mathrm{CuCl}_{2}$ eliminates pollution.

6. It has a stable etch quality rate under uniform process conditions.

7. This process is widely used in electronics, aerospace and precision engineering industries.

\section{- APPLICATION:}

Copper etching is mostly used in the printed circuit board (PCB) manufacturing for electronics application.

\section{CONCLUSION}

As an etchant, $\mathrm{CuCl}_{2}$ is commonly used in the manufacture of PCBs. It has a stable etch quality rate under uniform process conditions. The copper etching process should be completed at the highest possible etching temperature. The Baumé of etchant should be chosen around 32-33 Bé (2.33-2.5 Mol). These etching parameters would produce stable etch rate and low undercut in copper etching.

Also, environmental regulations push manufacturers to be more careful about environmental pollution occurred during/after etching process. The full regeneration of waste $\mathrm{CuCl}_{2}$ eliminates pollution. Surplus $\mathrm{CuCl}_{2}$, after regeneration process, can be sold to companies which are interested in further using for etching or recovering copper from solution.

\section{REFERENCES}

[1] D.M. Allen, The Principle and Practices of Photochemical Machining and Photo etching, Adam Hilger Publication, 1986

[2] W.T. Harris, Chemical Milling, Oxford University Press, 1976

[3] J.W. Dini, American Machinist (Special Report), 128, (1984), 113-128

[4] C.F. Coombs, Jr., (Ed), Printed Circuit Boards, McGraw-Hill, 1995 
[5] J.O.E.Clark, The Marconi Review, 26 (1961), 135-152

[6] S. Gowri, K.S. Indira, B.A. Shenoi, Metal Finishing, 64 (1966), 54-59

[7] E.C. Jubb, Plating, 139 (1964), 2202-2211

[8] M.J. Thomas, "Etching”, Technical Note (MacDermid (GB) Ltd.), 28 pages

W.C. Bosshart, Printed Circuit Boards- Design and Technology", Tata McGraw-Hill Publ., 1985 Batham, Electronic Production, 11 (1988), 101,103,107

[9] R.E. Markle, Industrial Finishing, May 1982, 47-49

[10] O. Çakir, Proc. of the First Mechanical Engineering Congress (Istanbul, Turkey), June 4-6, 1997, 464468

[11] Kenneth Mirski, Proc. Tech. Prog. Nat. Electronic Pack. And Prod. Conf., USA, 1981,196-207

[12] E.B. Khobotova, S.D. Gorobels, V.I. Larin, Zashchita Metallov, 23 (1987), 980-982

[13] D.G. Barrett, PCMI Journal, Issue No:46 (1991), 15-17

[14] D.M. Allen, O. Çakir, PCMI Journal, Issue No:52 (1993), 4-7

[15] O.Çakir, Proc. of the Int. Symposium on Municipal and Industrial Wastes and Their Treatment in 2000 (Treatment 2000) (Istanbul, Turkey), May 17-20, 2000, 396-401

[16] Allen D.M., Çakır O.: Copper Etching Economics, PCMI Journal, No:52, pp:4-7, 1993

[17] Çakır O.: Photochemical machining of copper and copper alloys, Proc. 3rd. Int. Conf. on Adv. Manufac. Tech. (ICAMT 2004), Malaysia, pp:60-64, 2004

[18] Allen D.M., Çakır O.: Comparison of $\mathrm{FeCl} 3$ and $\mathrm{CuCl} 2$ etchants in the photochemical machining of brass, Proc.of 6th Biennial Conf. on Engg. Sys. Des. and Analy., (ESDA 2002), Turkey, 7 pages, 2002 